\title{
Shift schedules, work factors, and mental health among onshore and offshore workers in the Norwegian petroleum industry
}

\author{
Mona BERTHELSEN ${ }^{1,2}$, Ståle PALLESEN ${ }^{2,3}$, Bjørn BJORVATN ${ }^{3,4}$ and Stein KNARDAHL ${ }^{1}$ \\ ${ }^{1}$ Department of Work Psychology and Physiology, National Institute of Occupational Health, Norway \\ ${ }^{2}$ Department of Psychosocial Science, Faculty of Psychology, University of Bergen, Norway \\ ${ }^{3}$ Norwegian Competence Center for Sleep Disorders, Haukeland University Hospital, Norway \\ ${ }^{4}$ Department of Public Health and Primary Health Care, Faculty of Medicine and Dentistry, University of Bergen, \\ Norway
}

Received September 3, 2014 and accepted January 5, 2015

Published online in J-STAGE February 18, 2015

\begin{abstract}
The purpose of the present study was to answer the following research questions: (1) Do workers in different shift schedules differ in mental distress? (2) Do workers in different shift schedules differ in neuroticism? (3) Do shift schedules differ in psychosocial work exposures? (4) Do psychosocial work exposures contribute to mental distress among onshore- and offshore workers? (5) Does neuroticism confound the association between work exposures and mental distress? Workers on six shift-schedules answered a questionnaire (1,471 of 2,628 employees). Psychological and social work factors were measured by QPS $_{\text {Nordic, }}$, mental distress was measured by HADS and neuroticism was measured by EPQ. The results showed 1) No differences in mental distress between workers in different shift schedules, 2) Revolving-shift workers reported higher neuroticism compared to day workers, 3) Swing-shift workers and revolving-shift workers reported lower job control compared to permanent-night and -day workers, 4) Job demands and role conflict were associated with more mental distress. Job control, role clarity, support, and leadership were associated with lower mental distress, 5) Neuroticism influenced the relationship between psychosocial work factors and mental distress. The present study did not find differences in mental distress between shift schedules. Job characteristics may be contributing factors when determining health effects of shift work.
\end{abstract}

Key words : Shift work, Psychosocial, Occupational, Personality, Mental distress

\section{Introduction}

Shift work, long working hours, and night work have been reported to impact negatively on workers' health ${ }^{1-5)}$. However, few studies have taken into account the many exposures during work that may confound associations

*To whom correspondence should be addressed. E-mail: Mona.Berthelsen@stami.no

(C)2015 National Institute of Occupational Safety and Health between working hours and health. The objectives of the present study were to elucidate effects of specific characteristics of shift work on mental distress and to determine the role of psychological and social work-exposure factors that may differ between shift schedules.

Major problems of studying effects of shift work are that (i) shift-work schedules differ in many parameters (e.g. time of day, duration of shift, shift rotation, length of recovery period), (ii) work tasks during night shifts may differ from work carried out during daytime, hence exposures 
during the work period may differ, and (iii) shift work may differ from day work in extraneous, non-work parameters that may confound conclusions. The petroleum industry illustrates the problems. Since onshore work generally is performed by workers living in their homes while offshore work naturally involves living away from ones homes, there are several factors that confound conclusions made from comparisons of offshore shift work with onshore work.

Explanations of links between shift work and mental health are speculative ${ }^{6}$. There are three potentially pathogenic pathways ${ }^{7,8)}$ : (I) Disruption of the circadian rhythm by variation of working hours that includes evenings or nights. This disrupts neurohumoral systems which in turn may affect mental health. (II) Sleep deprivation due to lack of compensatory sleep after shifts (homeostatic sleep regulation). (III) Challenges (stressors) to private life: working on evenings or at nights creates problems in meeting demands and expectations from family and friends ${ }^{9)}$. The present study sought to elucidate effects of shift-schedule characteristics specifically related to the three pathogenic pathways.

Mental-health problems in active working individuals tend to be light to moderate symptoms of depression or anxiety, commonly labeled mental or psychological distress ${ }^{11}{ }^{12}$. The evidence from studies comparing the effects of different shift systems on workers mental health is mixed ${ }^{5)}$. Cross-sectional studies have demonstrated that shift workers more often than day workers report irritability, nervousness, and anxiety ${ }^{2)}$, as well as mental distress ${ }^{4}$. An 11-wave panel study ${ }^{1)}$ found that working shifts for more than four years was associated with poor mental health (General Health Questionnaire). A review concluded that disruption of circadian rhythms over time may lead to mood disorders, neuroticism, anxiety, and depression $^{3)}$. On the other hand, a recent prospective study of nurses found that shift workers exhibited better mental health than day workers ${ }^{13)}$. Furthermore, a study ${ }^{14)}$ showed that workers with high levels of mental distress were more likely to change jobs within the company, between companies, or to reduce their working hours and leave a shift work job, compared to workers who maintained good mental health.

In many workplaces work tasks and staffing differ between regular day shifts and evening/nights. Hence, exposures during work may differ and confound associations between shift types and health outcomes. Several prospective studies have demonstrated that psychological and social working conditions may contribute to de- $\operatorname{pression}^{15,16,18-20)}$ and distress ${ }^{17,21)}$. Furthermore, one prospective study demonstrated both cross-lagged relationships as well as reverse causal relationships between demand, control, and support and indicators of mental health ${ }^{22)}$. The present study examines the association between psychological and social work factors and mental distress in both onshore and offshore shift-work environments.

The personality trait neuroticism, often labeled negative affectivity, may play a role in tolerance to shift work ${ }^{23)}$. Neuroticism and negative affectivity have been shown to influence the perception of psychological and social work environment ${ }^{24)}$ and be associated with anxious and depressive symptoms ${ }^{25)}$. Negative affectivity may therefore influence associations between psychological and social work factors and mental health and distress by being a mediator or confounder ${ }^{26,27)}$.

The present study sought to answer the following questions: (Q1) Do workers in different shift schedules differ in mental distress? (Q2) Do workers in different shift schedules differ in neuroticism? (Q3) Do shift schedules differ in psychological and social work exposures? (Q4) Onshore and offshore work environments: Do psychological and social work exposures contribute to mental distress? (Q5) Onshore and offshore work environments: Does neuroticism confound the association between work factors and mental distress?

\section{Subjects and Methods}

\section{Design}

The study is cross-sectional with respect to self-reported mental distress, psychological and social work factors, and neuroticism that were measured concomitantly with one questionnaire. The data were collected by a web-based questionnaire system which permits secure data collection, or by a paper and pencil questionnaire.

The effect of disruption of circadian rhythm may be investigated by comparing offshore permanent daytime (14 d) with permanent night shift (14 d), and by comparing swing shift (7 nights/7days) with permanent night shifts. Hence, the comparisons are made between shift workers with zero, seven or 14 nights. Results from studies on physiological and psychological adaptation to night work show that on average the body is fully adapted after five to six days ${ }^{10)}$. Hence, swing-shift workers may be in a constant state of adaptation to the shift schedule during the work period.

By comparing onshore permanent day work with rotat- 
Table 1. Response rates by company and web versus paper \& pencil questionnaire

\begin{tabular}{lcccc}
\hline \multirow{2}{*}{ Company } & Invited & \multicolumn{3}{c}{ Responses } \\
\cline { 3 - 4 } & & Web & Paper \& pencil & \\
\hline Onshore: & & & & \\
Company 1 & 828 & 336 & 0 & $40.6 \%$ \\
Company 2 & 51 & 33 & 0 & $64.7 \%$ \\
Offshore: & & & & \\
Company 1 & 110 & 72 & 0 & $65.5 \%$ \\
Company 2 & 705 & 313 & 228 & $76.7 \%$ \\
Company 3 & 934 & 367 & 122 & $52.4 \%$ \\
\hline Total & 2,628 & 1121 & 350 & $56.0 \%$ \\
\hline
\end{tabular}

ing shift work (day, evening and night), potential effects of disruption of circadian rhythms, sleep deprivation, and challenges to private life may be elucidated.

\section{Participants}

The 1,471 subjects who completed the survey were recruited from five companies. A total of 2,628 employees were invited (response rate 56\%) (Table 1). The organizations were contacted by e-mail and telephone and offered to participate in the study. No subjects were contacted directly. Both onshore and offshore workers from operator and contractor companies were recruited. Data were gathered from 2010 to 2011. In return for participating, the companies received written reports as well as oral presentations of results as a tool for organizational development and as an aid for monitoring the psychosocial work environment.

Prior to the data collection, employees and managers were informed about the survey aims and about the data collection procedures. Subsequently, all employees were mailed a letter with information about the survey as well as a personal log-in code to the web-questionnaire. The written information explained the aims of the study and assured that responses would be treated confidentially and in accordance with the guidelines and license from the Data Inspectorate. Informed consent was given by the respondents. Employees were given the opportunity to complete the questionnaire at work, but had also the opportunity to access the web-questionnaire at home or from any other location with Internet access. Each employee had the opportunity to log in to the web-questionnaire an unlimited number of times to change or to complete their answers during the period of data collection.

The study was approved by the Regional Committee for Medical and Health Research Ethics, Region WestNorway (REC).
In addition to a question about the employees' current job title in the questionnaire, three out of five companies supplied lists about each employees standard classification of occupations (STYRK) developed by Statistics Norway (www.ssb.no). STYRK is based on the International Standard Classification of Occupation (ISCO-88). All companies supplied lists of employees' address, age, sex and department affiliation. For the two companies not providing STYRK information, the classification was based on the job title provided by each subject.

In addition to shift schedules, the questionnaire addressed background information, sleep disturbances, use of sleep related medications, work organization, psychological and social factors at work, mechanical and chemical exposures, safety and risk perception, accidents, recovery after work, reproduction, personality, physical activity, alcohol use, smoking, shift work locus of control, work ability, mental health, and health complaints.

\section{Shift schedules}

Shift schedules were recorded by a hierarchy of questions starting with "Do you have a working hour arrangement that includes night work?", with the response categories, "yes" and "no". Offshore respondents answering "Yes" were then asked to specify his or her working arrangement with the following alternatives: "Permanent night shift", "Alternate shift 7 nights/7 days" (swing shift), "Alternate shift 7 days/7 nights (swing shift), "Full shift 14 days/14 nights every other work period" and "Other night work". Offshore respondents answering "No" were asked to specify his or her working hour arrangement using the following alternatives: "Permanently daytime", "Staggered shift" and "Other day work". The length of the shift schedules are normally $12 \mathrm{~h}$ a day.

Onshore workers answering "Yes" to night work, were asked to specify his or her working hour arrangement us- 
ing the following response categories: "Permanent night", "Revolving shift" and "Other night work". Onshore workers answering "no" to night work were asked to specify his or her working hour arrangement using the response categories "Permanent days", "2-shift" and "Other day work". At onshore installations in Norway the most frequent working pattern is a continuous six-week shift schedule, with five weeks at work and one week off. On week days the shift duration is normally $8 \mathrm{~h}$ and on weekends $12 \mathrm{~h}$. Most workers work either permanent daytime or revolving shifts (alternating between daytime, evening and night shift), but 2-shift (daytime, evening) are also used.

Permanent-night workers offshore had been working a shift schedule including night work for on average $13.3 \mathrm{yr}$ ( $\mathrm{SD}=8.6$ ), swing-shift workers (7 night/7 days) offshore for on average $11.7 \mathrm{yr}(\mathrm{SD}=8.0)$ and swing-shift workers with a 7 day/7 night rotation had been working nights for on average $13.1 \mathrm{yr}(\mathrm{SD}=9.4)$. Revolving-shift workers onshore had been working nights for on average $13 \mathrm{yr}$ $(\mathrm{SD}=8.0)$.

\section{Outcome measure}

The outcome measure comprises the Hospital Anxiety and Depression Scale (HADS). HADS consist of 14 items, with seven items alleged to measure anxiety and seven items alleged to measure depression ${ }^{12)}$. For example the statement "I feel tense or "wound up" reflects anxiety, with the response categories "most of the time" (3), "a lot of the time" (2), "from time to time" (1), and "not at all" (0). The statement "I still enjoy the things I used to enjoy" is a measure of a symptom of depression, with the response categories "definitely as much" (0), "not quite so much" (1), "only a little" (2) and "hardly at all" (3). Composite scores reflecting each respondents average score on the single items were calculated for the Anxiety (seven items, $\alpha=0.75$ ) and for the Depression (seven items, $\alpha=0.74$ ) subscale, respectively as well as for a total mental distress scale (all 14 items, $\alpha=0.84$ ).

\section{Psychological and social work factors}

Psychological and social work factors were measured by the General Questionnaire for Psychological and Social factors at Work, $\mathrm{QPS}_{\text {Nordic }}{ }^{28)}$. The following factors were studied: Job Demands (Quantitative demands, decision demands, learning demands, 10 items, $\alpha=0.73$ ), Job control (Control of decision, control of work pacing, positive challenges, 11 items, $\alpha=0.77$ ), Role conflict (three items, $\alpha=0.67$ ), Role clarity (three items, $\alpha=0.79$ ), Support from co-workers $\&$ immediate superior (five items, $\alpha=0.86$ ),
Fair $\&$ empowering leadership (six items, $\alpha=0.85$ ). The items were measured on a five-point rating scale with the following response alternatives: "very seldom or never" (1), "rather seldom" (2), "sometimes" (3), "rather often" (4), "very often or always" (5). Average score was calculated for all factors.

\section{Neuroticism}

Neuroticism was measured by the Eysenck Personality Questionnaire (EPQ), short version consisting of six items measuring Neuroticism ${ }^{29)}$. The items were answered along a four-point scale ranging from "almost never" (1), "quite seldom" (2), "quite almost" (3) to "almost always" (4). A composite score reflecting the respondents average score on the single items was calculated for Neuroticism (six items, $\alpha=0.68$ ).

\section{Statistical analyses}

All analyses were conducted by IBM SPSS Statistics version 21.

\section{Handling of missing values}

The dataset consisted of 1,027 (81.25\%) complete cases on 69 variables, giving $237(18.75 \%)$ cases with one or more missing values. The amount of missing values was 1,858 values out of 93,536 possible values (1.99\%). Missing values on the items measuring psychological and social work factors, neuroticism, and mental distress were imputed using multiple imputation under the normal model based on the Marcov Chain Monte Carlo (MCMC) method as recommended by Schafer and Graham ${ }^{30)}$. A total of ten datasets were simulated. The imputations were performed separately for each shift schedule group in order to preserve possible interactions between the various shifts. This method is considered appropriate under the assumption that data are missing at random. Multiple imputation procedures take the error variance between each simulated data set into account, and preserve important characteristics of the data set.

\section{Analyses}

Univariate Analysis of Co-Variance (ANCOVA) was conducted to answer research question 1) "Do workers in different shift schedules differ in mental distress?" and 2) "Do workers in different shift schedules differ in neuroticism?". Multivariate Analysis of Co-Variance (MANCOVA) was conducted to answer research question 3) "Do shift schedules differ in psychological and social work exposure?" The following pairs of shift schedules were 
Table 2. Pooled correlations between $\mathrm{QPS}_{\mathrm{Nordic}}$ scales and neuroticism and mental distress

\begin{tabular}{|c|c|c|c|c|c|c|c|c|}
\hline & 1 & 2 & 3 & 4 & 5 & 6 & 7 & 8 \\
\hline 1. Job demands & 1 & & & & & & & \\
\hline 2. Job control & $0.06^{*}$ & 1 & & & & & & \\
\hline 3. Role conflict & $0.37^{* *}$ & $-0.15^{* *}$ & 1 & & & & & \\
\hline 4. Role clarity & $-0.01^{\mathrm{ns}}$ & $0.27^{* *}$ & $-0.20^{* *}$ & 1 & & & & \\
\hline 5. Support from co-workers \& superior & $-0.14^{* *}$ & $0.33^{* *}$ & $-0.33^{* *}$ & $0.42^{* *}$ & 1 & & & \\
\hline 6. Fair \& empowering leadership & $-0.01^{\mathrm{ns}}$ & $0.42^{* *}$ & $-0.30^{* *}$ & $0.38^{* *}$ & $0.66^{* *}$ & 1 & & \\
\hline 7. Neuroticism & $0.14^{* *}$ & $-0.27^{* *}$ & $0.18^{* *}$ & $-0.23^{* *}$ & $-0.25^{* *}$ & $-0.30^{* *}$ & 1 & \\
\hline 8. Mental distress & $-0.21^{* *}$ & $-0.28^{* *}$ & $0.23^{* *}$ & $-0.25^{* *}$ & $-0.32^{* *}$ & $-0.30^{* *}$ & $0.65^{* *}$ & 1 \\
\hline Mean & 2.81 & 3.17 & 2.63 & 4.22 & 4.00 & 3.59 & 1.96 & 8.25 \\
\hline SD & 0.47 & 0.51 & 0.69 & 0.69 & 0.63 & 0.71 & 0.45 & 5.34 \\
\hline Minimum-maximum score & $1.0-4.6$ & $1.3-5.0$ & $1.0-5.0$ & $1.0-5.0$ & $1.6-5.0$ & $1.0-5.0$ & $1.0-3.5$ & $0.0-2.1$ \\
\hline
\end{tabular}

contrasted: permanent daytime onshore and revolving shift onshore, permanent daytime offshore and permanent night offshore, and permanent night offshore and swing shift offshore. Significant main effects of differences between the paired shift schedules were further examined by discriminant analysis ${ }^{31)}$. Discriminant analysis identifies one or more "variates" that differentiate the groups. The higher the correlation coefficient between the work factor and the "variate" (discriminant function), the more the work factor differentiates the shift-schedule groups on that "variate". The $\alpha$-level chosen was 0.01 . The factors role clarity, support from co-workers \& immediate superior, and fair $\&$ empowering leadership were negatively skewed more than 3 times their standard errors and thus did not meet the assumption of normality. The scales were logarithmic transformed using the LOG10 (6-variable) arithmetic transformation for negatively skewed variables.

Simple and multiple linear regression analyses with block design were conducted to test research question 4) Do psychological and social work exposures contribute to mental distress?" and 5) "Does neuroticism confound the association between psychological and social work factors and mental distress?". Analyses were performed for all offshore workers as one group and all onshore workers as one group. The $\alpha$-level chosen was 0.01 . All predictor variables were standardized before entered in the regression analysis in order to compare the strength of the regression effects across measurement scales and confidence intervals. In linear regression analysis the confidence interval is calculated for the unstandardized regression coefficients only, thus all variables had to be standardized prior to conducting the analyses. Control variables were sex, age, and work title (STYRK) reflecting level of education.

\section{Results}

\section{Participant characteristics}

The sample consisted of $86(6.8 \%)$ females and 1,170 (93.2\%) males. Mean age was $42.6(\mathrm{SD}=10.5$ years; range 20-68). Six different shift schedules were identified and analyzed among the respondents: $143(11.8 \%)$ worked permanent daytime onshore, 166 (13.7\%) worked revolving shift onshore, 44 (3.6\%) worked permanent night shift offshore, 464 (38.2\%) worked swing shift with a 7 night/7 day rotation offshore, and 187 (15.4\%) worked swing shift with a 7 day/7 night rotation offshore. Finally, 210 $(17.3 \%)$ worked permanent daytime offshore. For operator offshore workers and onshore workers shift schedules are generally fixed. However, for some specialist personnel actual working hours may vary from work period to work period and from installation to installation. In the present sample, respondents from one contractor company were excluded from the present analyses due to irregular and/ or unpredictable shift schedules. According to the STYRK classification of occupations, the three largest groups among the respondents were plant and machine operators and assemblers, professionals, and technicians and associate professionals. The rest of the categories comprised craft and related trade workers, clerks and armed forces and unspecified.

The two types of swing shift were treated as one group in all analyses due to lack of difference on exposure and outcome measures.

Most correlations between psychological and social work factors were low to moderate (Table 2). However, the correlation between support from co-workers \& im- 
mediate superior and fair \& empowering leadership was $\mathrm{r}=0.66$ which may pose a risk of multicollinearity in multiple regression models.

The prevalence of anxiety and depression among the offshore workers were generally lower than the onshore workers using both a cut off of $\geq 8$ (potential anxiety/ depression) and $\geq 11$ (anxiety/depression) on the anxiety and depression sub-scales. Among offshore workers, the prevalence of potential anxiety was $10.2 \%$ (90 out of 883 ) and for anxiety the prevalence was $1.2 \%$ (11 out of 883 ), while onshore workers showed a prevalence of $11.5 \%$ (34 out of 295) and 2.4\% (7 out of 295) respectively. Offshore workers showed a prevalence of $14.7 \%$ (130 out of 883) for potential depression and $2 \%$ (18 out of 883 ) for depression, while onshore workers showed a prevalence of $17.7 \%$ (52 out of 294) and 5.1\% (15 out of 294) respectively.

\section{(Q1) Do workers in different shift schedules differ in mental distress?}

There were no significant differences in mental distress between the contrasted shift schedule groups. Mental distress of onshore day-workers (mean $=0.57, \mathrm{SD}=0.38$ ) did not differ from that of revolving-shift workers onshore (mean $=0.69, \mathrm{SD}=0.40, \mathrm{~F}(1,294)=3.728, p=0.054)$. Offshore permanent-day workers (mean $=0.55, \mathrm{SD}=0.40$ ) with zero number of nights, were not different from permanentnight workers (mean $=0.53, \mathrm{SD}=0.38$ ) with 14 consecutive nights $(\mathrm{F}(1,251)=0.48, p=0.489)$. Swing-shift workers (mean $=0.58, \mathrm{SD}=0.36$ ) with 7 consecutive nights were not different in mental distress from permanent-night workers (mean $=0.53, \mathrm{SD}=0.38$ ) with 14 consecutive nights $(\mathrm{F}(1,675)=0.848, p=0.357)$.

(Q2) Do workers in different shift schedules differ in neuroticism?

Revolving-shift workers onshore (mean $=2.11, \mathrm{SD}=0.43$ ) reported significant higher level of neuroticism compared to permanent day workers onshore ((mean $=1.92, \mathrm{SD}=.45)$; $\mathrm{F}(1,291)=7.821, p=0.006)$. There were no significant differences in level of neuroticism between permanent day (mean $=1.88, \mathrm{SD}=0.47$ ) and permanent-night workers offshore $($ mean $=1.81, \mathrm{SD}=0.42 ; \mathrm{F}(1,224)=1.059, p=0.304)$ or between permanent-night (mean $=1.81, \mathrm{SD}=0.42$ ) and swing-shift workers offshore $(($ mean $=1.97, \mathrm{SD}=0.44) ; \mathrm{F}$ $(1,651)=4.540, p=0.33)$.

(Q3) Do shift schedules differ in psychological and social work exposures?

Differences in psychological and social work factors were found between onshore daytime and revolving-shift workers $(\mathrm{F}(6,293)=18.23, p<0.0001)$. Daytime-workers reported higher job control compared to revolving-shift workers (Table 3). Differences in psychological and social work factors were also found between offshore permanentnight workers and swing-shift workers $(\mathrm{F}(6,659)=5.69$, $p<0.0001)$. Permanent-night workers reported higher job control, fair \& empowering leadership and support from co-workers \& immediate superior compared to swing-shift workers. There were no statistical significant differences between permanent-daytime and permanent-night workers offshore.

(Q4) Onshore and offshore work environments: Do psychological and social work exposures contribute to mental distress?

We chose to collapse all offshore workers into one group and all onshore workers into another group when determining associations between work exposures and mental distress.

\section{Onshore workers}

Job control and support from co-workers \& immediate superior were associated with lower mental distress (Table $4 \mathrm{a}$, model 1 - sex, age and work title adjusted effects). Job demands and role conflict were associated with higher mental distress. There were no significant associations between role clarity, fair \& empowering leadership and mental distress. When all work factors were entered into a multiple model only job control was statistically significant associated with mental distress (Table 4a, multiple regression model, model 1). After adjusting for neuroticism, only role conflict remained significantly associated with mental distress among onshore workers (Table 4a, model 2 (simple model) - sex, age, work title and neuroticism adjusted effects). In the multiple model, none of the work factors were statistically significant after adjusting for neuroticism. The Durbin-Watson statistic was acceptable in all models. The Durbin-Watson test tests the assumption of independent errors. A value of 2 indicates that the error terms are uncorrelated. Values below 1 and above 3 gives cause for concern ${ }^{31}$.

\section{Offshore workers}

Job control, role clarity, support from co-workers \& immediate superior, and fair \& empowering leadership were associated with lower mental distress (simple models, Table $4 \mathrm{~b}$, model $1-$ sex, age and work title adjusted effects). Job demands and role conflict were associated with 
Table 3. Differences in psychological and social work factors between contrasted pairs of shift schedules. All analyses were adjusted for sex, age and education level (MANCOVA and discriminant analysis)

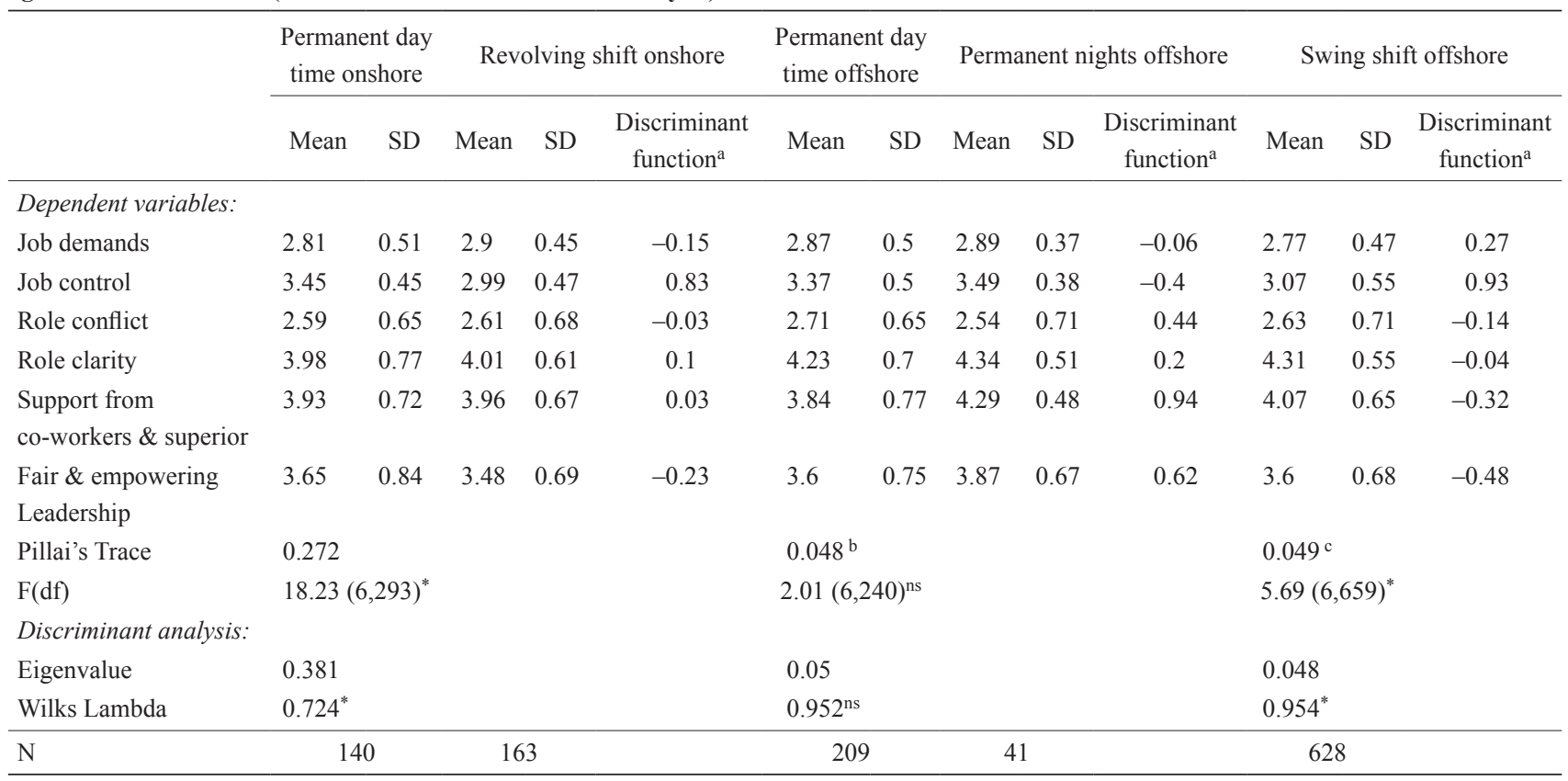

${ }^{*} p<0.0001$, ns: not significant

aStructure matrix: Pooled within-groups correlations between discriminating variables and standardized canonical discriminant functions.

${ }^{\mathrm{b}}$ Comparison between permanent daytime and permanent nights offshore.

${ }^{\mathrm{c} C o m p a r i s o n}$ between permanent nights and swing shift offshore

higher mental distress. When all work factors were entered into a multiple regression model job demands, job control, role clarity and fair \& empowering leadership were significantly associated with mental distress (Table 4b, model 1 (multiple model) - sex, age and work title adjusted effects). After adjusting for neuroticism, the associations between work factors and mental distress remained significant but the strength of the associations were reduced (Table 4b, model 2 (simple models) - sex, age, work title and neuroticism adjusted effects). In the multiple regression model, job demands, role clarity and support from coworkers \& immediate superior were associated with mental distress. The Durbin-Watson statistic was acceptable in all models. Due to the high correlation between support from co-workers \& immediate superior and fair \& empowering leadership $(\mathrm{r}=0.66)$, there may be a multicollinearity problem even though the results of a test of collinearity were acceptable. This potential problem was addressed by removing either support from co-workers \& immediate superior or fair \& empowering leadership from the multiple models. Both work factors were significantly associated to mental distress when entered without the other work factor in the multiple models. However, we chose to include both work factors in the multiple models because they represent different constructs. Of the same reason, the univariate association between each work factor and mental distress should be considered equally important as the unique contribution of each work factor to mental distress.

(Q5) Onshore and offshore work environments: Does neuroticism confound the association between psychological and social work factors and mental health?

Including neuroticism in the regression models generally reduced the associations between work factors and mental distress, but did not rule out all associations. This indicates that neuroticism accounted for some variation in mental distress, but that conditions in the work environment accounted for unique variation in mental distress.

\section{Discussion}

The present study did not detect significant differences in mental distress between various shift schedules. Shift workers onshore exhibited more neuroticism compared to day workers onshore. Onshore permanent-daytime workers reported higher levels of job control compared to revolving-shift workers onshore. Job demands, job control, role conflict and support from co-workers \& immediate 
Table 4a. Onshore workers: standardized regression coefficients (pooled) for each work factor on mental distress adjusted for sex, age and education level (model 1) and additionally adjusted for neuroticism (model 2)

\begin{tabular}{|c|c|c|c|c|c|c|c|}
\hline & \multicolumn{3}{|c|}{ Model 1} & \multicolumn{3}{|c|}{ Model 2} & \multirow[b]{2}{*}{ Durbin Watson } \\
\hline & B & $99 \% \mathrm{CI}$ & Adjusted $\mathrm{R}^{2}$ & B & $99 \% \mathrm{CI}$ & Adjusted $\mathrm{R}^{2}$ & \\
\hline \multicolumn{8}{|l|}{ Simple regression models: } \\
\hline Job demands & $0.18^{*}$ & {$[0.00$ to 0.36$]$} & 0.02 & 0.15 & {$[-0.02$ to 0.32$]$} & 0.43 & 2.06 \\
\hline Job control & $-0.35^{* * *}$ & {$[-0.51$ to -0.18$]$} & 0.12 & -0.16 & {$[-0.38$ to 0.05$]$} & 0.45 & 2.17 \\
\hline Role conflict & $0.29^{* * *}$ & {$[0.10$ to 0.48$]$} & 0.06 & $0.15^{*}$ & {$[0.01$ to 0.30$]$} & 0.45 & 2.08 \\
\hline Role clarity & -0.15 & {$[-0.34$ to 0.04$]$} & 0.01 & -0.01 & {$[-0.16$ to 0.14$]$} & 0.44 & 2.10 \\
\hline Support from co-workers \& superior & $-0.30^{* *}$ & {$[-0.53$ to -0.07$]$} & 0.10 & -0.12 & {$[-0.31$ to 0.07$]$} & 0.44 & 2.16 \\
\hline Fair \& empowering leadership & -0.20 & {$[-0.41$ to -0.01$]$} & 0.04 & -0.04 & {$[-0.19$ to 0.11$]$} & 0.43 & 2.15 \\
\hline Multiple regression model: & & & 0.18 & & & 0.47 & 2.15 \\
\hline Job demands & 0.06 & {$[-0.14$ to 0.25$]$} & & 0.08 & {$[-0.10$ to 0.26$]$} & & \\
\hline Job control & $-0.32^{* * *}$ & {$[-0.52$ to -0.12$]$} & & -0.18 & {$[-0.42$ to 0.08$]$} & & \\
\hline Role conflict & 0.17 & {$[-0.05$ to 0.38$]$} & & 0.09 & {$[-0.06$ to 0.25$]$} & & \\
\hline Role clarity & -0.03 & {$[-0.22$ to 0.16$]$} & & -0.05 & {$[-0.19$ to 0.08$]$} & & \\
\hline Support from co-workers \& superior & -0.24 & {$[-0.58$ to 0.10$]$} & & -0.13 & {$[-0.37$ to 0.11$]$} & & \\
\hline Fair \& empowering leadership & -0.08 & {$[-0.36$ to 0.19$]$} & & -0.09 & {$[-0.27$ to 0.09$]$} & & \\
\hline
\end{tabular}

$\mathrm{N}=321$

${ }^{*} p<0.01,{ }^{* *} p<0.001,{ }^{* * *} p<0.0001$

Table 4b. Offshore workers: standardized regression coefficients (pooled) for each work factor on mental distress adjusted for sex, age and education level (model 1) and additionally adjusted for neuroticism (model 2)

\begin{tabular}{|c|c|c|c|c|c|c|c|}
\hline & \multicolumn{3}{|c|}{ Model 1} & \multicolumn{3}{|c|}{ Model 2} & \multirow{2}{*}{ Durbin Watson } \\
\hline & B & $99 \% \mathrm{CI}$ & Adjusted $\mathrm{R}^{2}$ & B & $99 \% \mathrm{CI}$ & Adjusted $\mathrm{R}^{2}$ & \\
\hline \multicolumn{8}{|l|}{ Simple regression models: } \\
\hline Job demands & $0.20^{* * *}$ & [0.12 to 0.27$]$ & 0.06 & $0.10^{* * *}$ & [0.04 to 0.17$]$ & 0.45 & 1.83 \\
\hline Job control & $-0.25^{* * *}$ & {$[-0.33$ to -0.17$]$} & 0.08 & $-0.09^{*}$ & {$[-0.16$ to -0.02$]$} & 0.43 & 1.83 \\
\hline Role conflict & $0.20^{* * *}$ & {$[0.12$ to 0.28$]$} & 0.05 & $0.10^{* * *}$ & {$[0.03$ to 0.16$]$} & 0.44 & 1.84 \\
\hline Role clarity & $-0.29^{* * *}$ & {$[-0.37$ to -0.20$]$} & 0.09 & $-0.15^{* * *}$ & {$[-0.22$ to -0.08$]$} & 0.45 & 1.86 \\
\hline Support from co-workers \& superior & $-0.32^{* * *}$ & {$[-0.40$ to -0.24$]$} & 0.13 & $-0.18^{* * *}$ & {$[-0.25$ to -0.12$]$} & 0.45 & 1.84 \\
\hline Fair \& empowering leadership & $-0.35^{* * *}$ & {$[-0.42$ to -0.27$]$} & 0.14 & $-0.16^{* * *}$ & {$[-0.23$ to -0.09$]$} & 0.44 & 1.83 \\
\hline Multiple regression model: & & & 0.22 & & & 48 & 1.86 \\
\hline Job demands & $0.18^{* * *}$ & {$[0.10$ to 0.26$]$} & & $0.10^{* * *}$ & {$[0.03$ to 0.17$]$} & & \\
\hline Job control & $-0.11^{* *}$ & {$[-0.20$ to -0.03$]$} & & -0.03 & {$[-0.10$ to 0.05$]$} & & \\
\hline Role conflict & 0.02 & {$[-0.07$ to 0.10$]$} & & 0.01 & {$[-0.06$ to 0.07$]$} & & \\
\hline Role clarity & $-0.15^{* * *}$ & {$[-0.24$ to -0.06$]$} & & $-0.09^{* *}$ & {$[-0.16$ to -0.02$]$} & & \\
\hline Support from co-workers \& superior & -0.07 & {$[-0.17$ to 0.03$]$} & & $-0.09^{*}$ & {$[-0.17$ to -0.00$]$} & & \\
\hline Fair \& empowering leadership & $-0.18^{* * *}$ & {$[-0.29$ to -0.08$]$} & & -0.06 & {$[-0.15$ to 0.03$]$} & & \\
\hline
\end{tabular}

$\mathrm{N}=914$

${ }^{*} p<0.01,{ }^{* *} p<0.001,{ }^{* * *} p<0.0001$

superior were univariately associated with mental distress among onshore workers, however, only job control remained statistical significant when controlled for all work factors.

Offshore permanent-night workers reported higher levels of job control, support from co-workers \& immediate superior, and fair and empowering leadership compared to swing-shift workers offshore. Among offshore workers, all work factors were univariately associated with mental distress. However, only job demands, job control, role clarity and fair \& empowering leadership remained statistically significant when controlled for all work factors.

Neuroticism was generally found to attenuate the associations between work factors and mental distress indicat- 
ing potential confounding.

\section{(Q1) Do workers in different shift schedules differ in} mental distress?

The mechanisms behind a negative impact of night work and shift work on workers mental health are assumed to be disruption of the body's circadian rhythm, sleep deprivation, and challenges to private life. The present study observed no effect of night work or shift work on workers' mental distress. These findings are in contrast to those of Ljoså, Tyssen and $\mathrm{Lau}^{4)}$, who found that offshore workers working shifts including night work exhibited a higher level of mental distress measured by the Hopkins Symptom Check List-5 (HSCL-5) compared to day workers. Bara and Arbers ${ }^{1)}$ eleven-wave study among British workers found that shift work for more than four years was prospectively associated with poor mental health measured by the General Health Questionnaire (GHQ).

In determining potential effects of shift work and night work on workers health it is important to know the workers' exposure history. On average, the workers in the present study had been working shift for more than $12 \mathrm{yr}$. It is reasonable to assume that these workers have high tolerance for working shift and night work. Thus, potential negative health effects are likely to be underestimated in the present study. Studies on selection into shift work have found that age, sleep pattern, lifestyle habits, intention to leave the work place, and actual change from shift work to day time work to be potential selection mechanisms $^{13,32-35)}$.

According to the "Regulation on health requests for workers at offshore installations in the Petroleum industry" (The Norwegian Health Inspectorate, IS 1879, 2011), all offshore workers must have a $2 \mathrm{yr}$ valid health certificate, stating that they have no physical or mental illnesses that may affect the workers' work ability offshore. No such certificate is requested from onshore workers. It is also possible that mental health problems offshore, is underreported due to fear of not obtaining a health certificate, or because the present sample consist of mostly men who tend to underreport anxiety and depression symptoms ${ }^{36)}$.

Another explanation for the present findings may be that the relationship between shift work and mental distress is effectively buffered by long recovery periods, getting enough sleep, and a clockwise shift rotation system.

Mental-health problems in active working individuals tend to be light to moderate symptoms of depression or anxiety ${ }^{11,12)}$. The Hospital Anxiety and Depression scale was developed as a screening tool to assess the presence of symptoms of anxiety and depression in general medical out-patient clinics ${ }^{10)}$, but has been validated in both clinical and non-clinical populations ${ }^{37,38)}$. Evidence shows that the HADS performs satisfactory as a screening tool for symptoms of anxiety and depression ${ }^{39)}$. It is reasonable to assume that severe symptoms of anxiety and depression (cases) are a low-frequent phenomenon in such populations. However, the HADS should detect mild to moderate symptoms in the context of the present study.

\section{(Q2) Do workers in different shift schedules differ in} neuroticism?

Onshore shift workers reported higher levels of neuroticism compared to onshore day workers. Shift workers onshore must cope with a 3-rotation schedule (days, evenings and nights), and thus are more prone to shift rotation issues of disruption of circadian rhythm, sleep problems, different rotation directions, early day shift, short recovery period after night work, and work-family interference, all of which are putative variables that may affect with mental health.

The present findings do not permit conclusions on neuroticism as a major selection mechanism out of shift work. It may be that workers high in neuroticism change to onshore work. It may also be that shift workers become more neurotic over the years of shift work ${ }^{40)}$. Harrington ${ }^{41}$ ) concluded that neuroticism in itself is not a predictor of health-related shift problems.

(Q3) Differences in psychological and social work exposures between shift schedules

How workers experience their work environment may buffer or amplify potential negative health consequences of shift work. Shift workers employed at onshore gas installations reported less job control compared to day workers. The result is in line with findings from a study on U.K. oil industry personnel ${ }^{42)}$. A similar difference in experienced work environment was not detected among permanent-day workers versus permanent-night workers at oil rigs in the present study. Thus, the present result does not replicate the findings of Parkes ${ }^{42}$. Interestingly, the present findings show that swing-shift workers at oil rigs reported less job control, less support from co-workers \& immediate superior, and less fair \& empowering leadership compared to permanent-night workers. Swing-shift workers have to entrain their rhythms to new sleep-wake schedules twice during their work period offshore, while permanent-night workers only have to adapt once during their work period. Thus it seems that workers working the 
most "stressfull" shift schedules both onshore and offshore experience less control of work intensity and decisions regarding the work they performs.

\section{(Q4) Associations between work factors and mental} distress

Systematic reviews have identified psychological job demands as a risk factor for depression and anxiety ${ }^{19)}$. These findings were reproduced in the present study both among onshore and offshore workers, but only among offshore workers when all work factors and neuroticism were accounted for.

Systematic reviews have identified job control as a protective factor for mental distress ${ }^{21)}$. The present study supports such a relationship both in onshore and offshore environment only if neuroticism was omitted from the analysis. The present findings are partly in line with findings from a study of Norwegian onshore and offshore workers showing an association between control of decision and psychological health among offshore workers but not among onshore workers ${ }^{43)}$. Control of decision is one of the QPS Nordic $_{\text {subscales included in the job control }}$ dimension. In the present study, onshore workers exhibited a regression coefficient of 0.18 between job control and mental distress in the fully adjusted analysis, indicating some theoretical significance.

In both onshore and offshore environments, role conflict was only associated with mental distress in the unadjusted analysis. Role conflict was the most reliable risk factor for mental distress in the study by Finne, Christensen and Knardahl ${ }^{44)}$ and the study of nurses' aides by Eriksen, Tambs, and Knardahl ${ }^{17)}$.

Role clarity was associated with lower mental distress among offshore workers, but not among onshore workers. Our findings are thus partly supported by Finne and colleagues ${ }^{44)}$ who found an association between role clarity and mental distress in a general population. One explanation for why role clarity seems important for mental distress in offshore settings may be the strong emphasis on safety offshore.

Reviews have identified support from co-workers as a potential positive factor for health ${ }^{21,45)}$. Support from coworkers \& immediate superior was associated with lower mental distress among offshore workers, but only in the unadjusted analysis among onshore workers. Hence, the present results are somewhat in accordance with previous findings.

The leadership dimension was associated with lower mental distress among offshore workers only. The results are consistent with results from a prospective study examining the same work factors as the present study ${ }^{44)}$. The correlation between Support from co-workers \& immediate superior and fair \& empowering leadership were relatively high in the present study $(\mathrm{r}=0.66)$, and as earlier pointed out may pose a risk of multicollinearity in multiple regressions. This may explain the opposite results for onshore and offshore workers, and why support from co-workers \& immediate superior and not fair \& empowering leadership is associated with mental distress among offshore workers when adjusting for neuroticism.

\section{Methodological considerations}

All data in the present study were subjective reports recorded at the same point in time. The shift schedules should be rather constant over time and not subjected to (serious) recall bias. Hence, data on shift schedules should be relative free of bias. All other data may be subjected to reporting bias which may influence both exposure and outcome measures, and may inflate associations ${ }^{46)}$. The QPS $_{\text {Nordic }}$ was constructed in a way that should attenuate reporting bias ${ }^{28)}$ by avoiding negative/positive connotations in response scales, use verbal labels for all response categories, and reversing some of the items. The instruments measuring work factors, neuroticism, and mental health were rated on different scales. Even after controlling for neuroticism, conditions in the work environment were related to mental distress. However, Spector, Zapf, Chen and Frese ${ }^{27)}$ maintained that including a measure of negative affectivity when investigating stressor-strain relations should be avoided. The problem with the partialing procedure is that it removes variance shared with negative affectivity regardless of the cause of correlations between negative affectivity and other variables ${ }^{27)}$. Thus, we risk overadjustment by controlling for negative affectivity in the regression analyses. Associations between psychological and social work factors and mental distress have also been found in studies using work exposures assessed by observation or interview ${ }^{47)}$ and diagnostic interviews as health outcome ${ }^{48)}$. Hence, we cannot conclude that the observed associations are due to common method bias. Furthermore, neuroticism is a relatively stable personality trait that describes the individuals' tendency to experience negative emotions ${ }^{29}$ ), whereas mental distress is a state. The two concepts are expected to be distinct, but related ${ }^{25)}$. The present study does not allow conclusions on why the associations between work factors and mental distress were attenuated when neuroticism was controlled in the regressions. Neuroticism may be a mediator or a 
confounder in such relationships ${ }^{24-27)}$.

Another potential problem is "reverse causality". Workers may report poor working conditions because they are feeling anxious or depressed. Prospective studies have demonstrated that the relationship between work characteristics and mental distress may be both "normal" as assumed in the present study, or "reversed" or "reciprocal" ${ }^{22,49)}$. Thus, the present study gives a contribution to the field by examining relationships in two different work environments.

\section{Implications for practice and research}

Each of the work factors examined in the present study represents different constructs that may interact and affect mental distress in various ways ${ }^{28)}$. Therefore, we consider it important to take many aspects of work environments into account when drawing conclusions on the how and why work may affect the health of workers. For designing interventions at the work place one needs to know the specific problems that need attention. For example role conflict and job control call for different actions to be improved.

The present results indicate somewhat different patterns of associations between work factors and mental distress in the onshore environment as opposed to the offshore environment. However, the present study cannot conclude on why some work factors are associated with mental distress offshore and not onshore. In order to draw conclusions of effects shift work and night work on mental distress, there is a need for careful measurements of time schedules as well as exposures during work over time. Prospective designs including three or more measurement points, with different time lags are needed.

\section{Conclusion}

The present study did not find differences in mental distress between workers in different shift schedules. Workers in both onshore and offshore settings working a shift schedule that requires multiple changes in circadian rhythm, reported lower levels of job control than day workers and permanent-night workers, indicating that job characteristics may be important to take into account when determining health effects of shift work in future studies. Job demands seem to be a risk factor of mental distress in offshore settings, whereas job control, role clarity and fair and empowering leadership seems to be protective of mental distress.

\section{Acknowledgements}

The research described in this paper was funded by the Research Council of Norway, as part of the Petromaks program (Optimal Management of Petroleum resources). The authors would also like to thank Shahrooz Elka and Monica Skorstad for their contribution to the data collection, and Bjørn Lau for his contribution to design of the study and data collection.

\section{References}

1) Bara AC, Arber S (2009) Working shifts and mental health-findings from the British Household Panel Survey (1995-2005). Scand J Work Environ Health 35, 361-7. [Medline] [CrossRef]

2) Collins A, Matthews V, McNamara R (2000) Fatigue, Health and Injury among Seafarers and Workers on Offshore Installations: A Review. Cardiff: Cardiff University, Seafarers International Research Centre. Research Project 461 appendix 1.

3) Costa G (2010) Shift work and health: current problems and preventive actions. Saf Health Work 1, 112-23. [CrossRef] [Medline]

4) Ljoså $\mathrm{CH}$, Tyssen R, Lau B (2011) Mental distress among shift workers in Norwegian offshore petroleum industryrelative influence of individual and psychosocial work factors. Scand J Work Environ Health 37, 551-5. [CrossRef] [Medline]

5) Tucker P, Knowles SR (2008) Review of studies that have used the Standard Shiftwork Index: evidence for the underlying model of shiftwork and health. Appl Ergon 39, 550-64. [Medline] [CrossRef]

6) Taylor E, Briner RB, Folkard S (1997) Models of shiftwork and health: an examination of the influence of stress on shiftwork theory. Hum Factors 39, 67-82. [CrossRef] [Medline]

7) Knutsson A (1989) Shift work and coronary heart disease. Scand J Soc Med Suppl 44, 1-36. [Medline]

8) Knutsson A (2003) In-depth review: shift work. Health disorders of shift workers. Occup Med (Chic Ill) 53, 103-8 [CrossRef].

9) Nielsen MB, Tvedt SD, Matthiesen SB (2013) Prevalence and occupational predictors of psychological distress in the offshore petroleum industry: a prospective study. Int Arch Occup Environ Health 86, 875-85. [CrossRef] [Medline]

10) Parkes KR (2012) Shift schedules on North Sea oil/ gas installations: a systematic review of their impact on performance, safety and health. Saf Sci 50, 1636-51. [CrossRef]

11) Massé R, Poulin C, Dassa C, Lambert J, Bélair S, Battaglini A (1998) The structure of mental health: Higher-order conformatory factor analyses of psychological distress 
and well-being measures. Soc Indic Res 45, 475-504. [CrossRef]

12) Zigmond AS, Snaith RP (1983) The hospital anxiety and depression scale. Acta Psychiatr Scand 67, 361-70. [CrossRef] [Medline]

13) Nabe-Nielsen K, Garde AH, Albertsen K, Diderichsen F (2011) The moderating effect of work-time influence on the effect of shift work: a prospective cohort study. Int Arch Occup Environ Health 84, 551-9. [CrossRef] [Medline]

14) De Raeve L, Kant I, Jansen NWH, Vasse RM, van den Brandt PA (2009) Changes in mental health as a predictor of changes in working time arrangements and occupational mobility: results from a prospective cohort study. J Psychosom Res 66, 137-45. [Medline] [CrossRef]

15) Rugulies R, Bültmann U, Aust B, Burr H (2006) Psychosocial work environment and incidence of severe depressive symptoms: prospective findings from a 5-year follow-up of the Danish work environment cohort study. Am J Epidemiol 163, 877-87. [CrossRef] [Medline]

16) Ylipaavalniemi J, Kivimäki M, Elovainio M, Virtanen $M$, Keltikangas-Järvinen L, Vahtera J (2005) Psychosocial work characteristics and incidence of newly diagnosed depression: a prospective cohort study of three different models. Soc Sci Med 61, 111-22. [Medline] [CrossRef]

17) Eriksen W, Tambs K, Knardahl S (2006) Work factors and psychological distress in nurses' aides: a prospective cohort study. BMC Public Health 6, 290. [CrossRef] [Medline]

18) Nielsen ML, Rugulies R, Christensen KB, Smith-Hansen L, Kristensen TS (2006) Psychosocial work environment predictors of short and long spells of registered sickness absence during a 2-year follow up. J Occup Environ Med 48, 591-8. [Medline] [CrossRef]

19) Bonde JPE (2008) Psychosocial factors at work and risk of depression: a systematic review of the epidemiological evidence. Occup Environ Med 65, 438-45. [CrossRef] [Medline]

20) Marchand A, Blanc MÈ (2011) Occupation, work organisation conditions and the development of chronic psychological distress. Work 40, 425-35. 10.3233/WOR2011-1254 [Medline]

21) Stansfeld S, Candy B (2006) Psychosocial work environment and mental health - a meta-analytic review. Scand J Work Environ Health 32, 443-62. [Medline] [CrossRef]

22) de Lange AH, Taris TW, Kompier MAJ, Houtman ILD, Bongers PM (2005) Different mechanisms to explain the reversed effects of mental health on work characteristics. Scand J Work Environ Health 31, 3-14. [Medline] [CrossRef]

23) Saksvik IB, Bjorvatn B, Hetland H, Sandal GM, Pallesen S (2011) Individual differences in tolerance to shift worka systematic review. Sleep Med Rev 15, 221-35. [Medline] [CrossRef]

24) Paterniti S, Niedhammer I, Lang T, Consoli SM (2002) Psychosocial factors at work, personality traits and depressive symptoms. Longitudinal results from the GAZEL Study. Br J Psychiatry 181, 111-7. 10.1192/ bjp.181.2.111 [Medline]

25) Näswall K, Sverke M, Hellgren J (2005) The moderating role of personality characteristics on the relationship between job insecurity and strain. Work Stress 19, 37-49. [CrossRef]

26) Parkes KR (1990) Coping, negative affectivity, and the work environment: additive and interactive predictors of mental health. J Appl Psychol 75, 399-409. [CrossRef] [Medline]

27) Spector PE, Zapf D, Chen PY, Frese M (2000) Why negative affectivity should not be controlled in job stress research: don't throw out the baby with the bath water. J Organ Behav 21, 79-95. [CrossRef]

28) Dallner M, Elo AL, Gamberale F, Hottinen V, Knardahl S, Lindström K, Skogstad A, Ørhede E (2000) Validation of the General Nordic Questionnaire (QPSNordic) for psychological and social factors at work. Nordic Council of Ministers, Copenhagen.

29) Eysenck HJ (1958) A short questionnaire for the measurement of two dimensions of personality. J Appl Psychol 42, 14-7. [CrossRef]

30) Schafer JL, Graham JW (2002) Missing data: our view of the state of the art. Psychol Methods 7, 147-77. [CrossRef] [Medline]

31) Field A (2005) Discovering Statistics Using SPSS. 2nd Ed. SAGE Publications, London.

32) Jansen NW, van Amelsvoort LG, Kristensen TS, van den Brandt PA, Kant IJ (2003) Work schedules and fatigue: a prospective cohort study. Occup Environ Med 60 Suppl 1, i47-53. [Medline] [CrossRef]

33) Knutsson A, Åkerstedt T (1992) The healthy worker effect: self-selection among Swedish shift workers. Work Stress 6 , 163-7. [CrossRef]

34) Nabe-Nielsen K, Garde AH, Tüchsen F, Hogh A, Diderichsen F (2008) Cardiovascular risk factors and primary selection into shift work. Scand J Work Environ Health 34, 206-12. [Medline] [CrossRef]

35) van Amelsvoort LG, Schouten EG, Kok FJ (2004) Impact of one year of shift work on cardiovascular disease risk factors. J Occup Environ Med 46, 699-706. [Medline] [CrossRef]

36) Hunt M, Auriemma J, Cashaw AC (2003) Self-report bias and underreporting of depression on the BDI-II. J Pers Assess 80, 26-30. [CrossRef] [Medline]

37) Johnston M, Pollard B, Hennessey P (2000) Construct validation of the hospital anxiety and depression scale with clinical populations. J Psychosom Res 48, 579-84. [Medline] [CrossRef]

38) Crawford JR, Henry JD, Crombie C, Taylor EP (2001) Normative data for the HADS from a large non-clinical sample. Br J Clin Psychol 40, 429-34. [Medline] [CrossRef]

39) Spinhoven P, Ormel J, Sloekers PPA, Kempen GIJM, Speckens AEM, Van Hemert AM (1997) A validation study 
of the Hospital Anxiety and Depression Scale (HADS) in different groups of Dutch subjects. Psychol Med 27, 363-70. [Medline] [CrossRef]

40) Härmä M (1993) Individual differences in tolerance to shiftwork: a review. Ergonomics 36, 101-9. [Medline] [CrossRef]

41) Harrington JM (2001) Health effects of shift work and extended hours of work. Occup Environ Med 58, 68-72. [CrossRef]

42) Parkes KR (2003) Shiftwork and environment as interactive predictors of work perceptions. J Occup Health Psychol 8, 266-81. [CrossRef] [Medline]

43) Bjerkan AM (2011) Work and health: a comparison between Norwegian onshore and offshore employees. Work 40, 125-42. 10.3233/Wor-2011-1214 [Medline]

44) Finne LB, Christensen JO, Knardahl S (2014) Psychological and social work factors as predictors of mental distress: a prospective study. PLoS ONE 9 (7): e102514. [Crossref]

45) Nieuwenhuijsen K, Bruinvels D, Frings-Dresen M (2010) Psychosocial work environment and stress-related disorders, a systematic review. Occup Med (Lond) 60,
277-86. [CrossRef] [Medline]

46) Podsakoff PM, MacKenzie SB, Lee JY, Podsakoff NP (2003) Common method biases in behavioral research: a critical review of the literature and recommended remedies. J Appl Psychol 88, 879-903. [CrossRef] [Medline]

47) Griffin JM, Greiner BA, Stansfeld SA, Marmot M (2007) The effect of self-reported and observed job conditions on depression and anxiety symptoms: a comparison of theoretical models. J Occup Health Psychol 12, 334-49. [CrossRef] [Medline]

48) Waldenström K, Ahlberg G, Bergman P, Forsell Y, Stoetzer U, Waldenström M, Lundberg I (2008) Externally assessed psychosocial work characteristics and diagnoses of anxiety and depression. Occup Environ Med 65, 90-6. [CrossRef] [Medline]

49) de Lange AH, Taris TW, Kompier MAJ, Houtman ILD, Bongers PM (2004) The relationship between work characteristics and mental health: Examining normal, reversed and reciprocal relationships in a 4-wave study. Work Stress 18, 149-66. [CrossRef] 